\title{
Use of microlysimeters to measure evaporation from sandy soils
}

\author{
Carl C. Daamen ${ }^{*, a}$, L.P. Simmonds ${ }^{a}$, J.S. Wallace ${ }^{\mathrm{b}}$, K.B. Laryea ${ }^{\mathrm{c}}$, \\ M.V.K. Sivakumar ${ }^{d}$ \\ "Soil Science Department, University of Reading. London Road, Reading RGI 5AQ, UK \\ 'Institute of Hy'drology, Wallingford OX10 8BB, UK \\ 'ICRISAT, Patancheru P.O., Andhra Pradesh 502 324, India \\ "ICRISAT, Sahelian Center, B.P. 12404, Niamey, Niger \\ (Received 20 November 1992; revision accepted 8 March 1993)
}

\begin{abstract}
Evaporation from soil can be a major component of crop water balance and land surface energy balance. A number of different applications of the microlysimeter method to measure evaporation from soil have been used in recent studies. Microlysimeters were used extensively in three sandy soils for this study. Measurement of evaporation from microlysimeters with different dimensions and of different ages allows discussion of the sources of error inherent in the method.

The evaporation recorded from microlysimeters of diameters $214 \mathrm{~mm}, 152 \mathrm{~mm}$ and $51 \mathrm{~mm}$ was not significantly different. A comparison of $100 \mathrm{~mm}$ and $200 \mathrm{~mm}$ deep microlysimeters showed that depth had no significant influence during the first 2 days after extraction from the soil profile. For periods beginning 2 or more days after rain. significant differences in evaporation owing to depth may not occur for up to 7 days. Soil cores extracted at different times showed significant differences in evaporation immediately following a rain event, and no significant differences 2 or more days thereafter. This period of significant difference was extended to about 4 days when the method was used within a crop (i.e. root extraction of water in the field significant). A protocol for use of microlysimeters is developed from these results.
\end{abstract}

\section{Introduction}

The development of cropping systems that use water more efficiently is becoming increasingly important in the semi arid tropics. In these environments, evaporation from the soil surface is a significant component in the crop water balance (up to $60 \%$ of seasonal rainfall, Cooper et al., 1983). Studies of surface energy balance, up to the scale of global circulation models, must also include this latent energy flux. Evaporation from the soil, $E_{\mathrm{s}}$, can be measured or estimated in a number of ways (e.g. Ritchie, 1972; Arkin et al., 1974; 


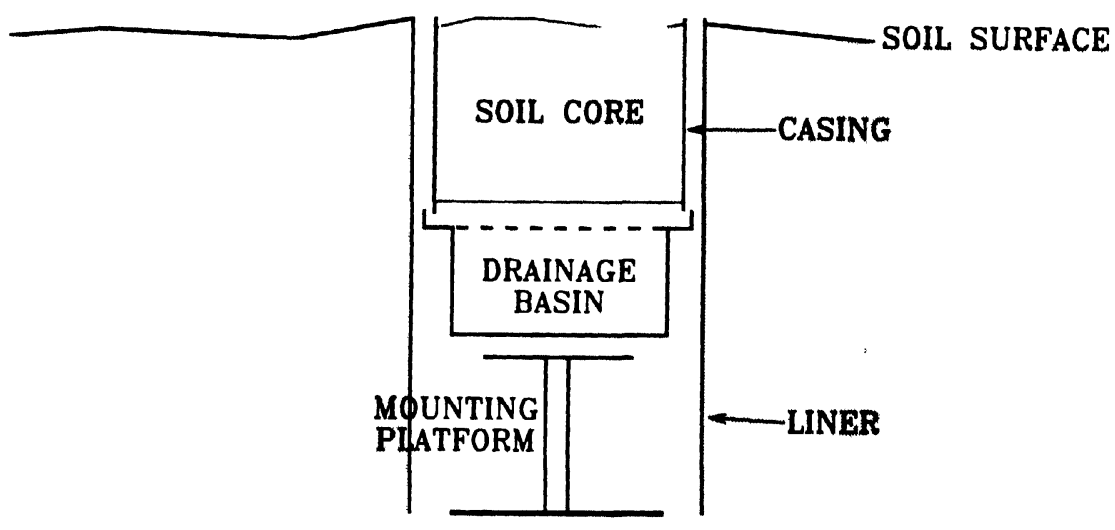

Fig. 1. Microlysimeter ( = soil core + casing + drainage basin $)$ mounted in liner tube

Ashktorab et al., 1989): the microlysimeter method (Boast, 1986) is arguably the most simple, direct and independent measurement of $E_{\mathrm{s}}$.

Microlysimeters are small isolated volumes of bare soil (typically $1-3 \mathrm{~kg}$ ) mounted flush with or slightly above the soil surface (Fig. 1) and weighed daily (or more frequently) to determine water loss. These soil cores can be extracted from and mounted in the soil beneath a crop canopy allowing separation of $E_{\mathrm{s}}$ fluxes from transpiration fluxes - an important distinction in crop water balance studies.

Table 1

Dimensions and useable lifetime of microlysimeters used in field studies

\begin{tabular}{lccl}
\hline Source & $\begin{array}{l}\text { Internal } \\
\text { diameter } \\
(\mathrm{mm})\end{array}$ & $\begin{array}{l}\text { Depth } \\
(\mathrm{mm})\end{array}$ & $\begin{array}{l}\text { Useable } \\
\text { Lifetime } \\
\text { (days) }\end{array}$ \\
\hline Boast and Robertson (1982) & 76 & 146 & - \\
& & 106 & - \\
Walker (1983) & 76 & 70 & $1-2$ \\
$\quad$ (see also Boast, 1986) & & 120 & $8-10$ \\
Shawcroft and Gardner (1983) & 203 & 200 & crop season \\
$\quad$ (see also Boast, 1986) & & 100 & (water added) \\
& 150 & 50 & crop season \\
(water added) & or 2 \\
Martin et al. (1985) & & 200 & 6 \\
Lascano and Van Bavel (1986) & 74 & 130 & 1 \\
Matthias et al. (1986) & 76 & 150 & 2 \\
Villalobos and Fereres (1990) & 200 & 300 & 1 \\
Allen (1990) & 100 & 150 & \\
Wallace et al. (1992) & 150 & 300 & \\
\hline
\end{tabular}

'Laboratory experiment. 
A number of authors have employed this method (Table 1) and the possible sources of error in the measurement of $E_{\mathrm{s}}$ have been discussed. Errors may occur if the soil within a microlysimeter has a significantly different water content or temperature to that of the surrounding soil. Specifically, if a onedimensional flux of water and energy can be assumed in the field, the main sources of error are: (1) the boundary to water flow imposed at the base of the microlysimeter at the time of soil core extraction; (2) the termination of root extraction of water from the soil core once it is isolated in the microlysimeter; (3) the disturbance of the soil in the extraction process; (4) the conduction of heat through the microlysimeter casing.

The magnitude of these errors depends on the width and depth of the microlysimeter used and the time since the soil core was extracted from the soil profile. These details of microlysimeter use vary considerably (Table 1).

The laboratory study of Boast and Robertson (1982) and the field study of Shawcroft and Gardner (1983) were the only ones in Table 1 designed to consider the effects of the sources of error of the microlysimeter method. These authors only considered the effect of lysimeter depth (i.e. the boundary to water flow at the base) with Shawcroft and Gardner using the same lysimeters for a whole season (Boast, 1986).

The objective of this paper is to consider which diameter, depth and useable lifetime are the most appropriate for microlysimeters used in field studies on sandy soils. A protocol for use of microlysimeters in water balance studies is proposed.

\section{Materials and methods}

The studies described here were conducted in three locations with sandy soils: the ICRISAT Center, Hyderabad, India on an Alfisol-Soil Taxonomy/ Luvisol-FAO System (66-79\% sand, 6\% silt, 15-28\% clay); the ICRISAT Sahelian Center, Niamey, Niger on an Alfisol-Soil Taxonomy/Arenosol-FAO System ( $91 \%$ sand, $5 \%$ silt, $4 \%$ clay); and the University of Reading farm, Sonning, UK on the Rowland Series ( $80 \%$ sand, $12 \%$ silt, $8 \%$ clay).

The microlysimeter casing and the pipe lining the holes in which the microlysimeters were mounted, were both constructed from unplasticised polyvinyl chloride (PVC) pipe. Unplasticised PVC has a heat capacity of $0.95 \mathrm{~J} \mathrm{~g}^{-1} \mathrm{~K}^{-1}$ at $25^{\circ} \mathrm{C}$ (Koleske and Wartman, 1969) and a thermal conductivity of 0.16 $0.17 \mathrm{~W} \mathrm{~m}^{-1} \mathrm{~K}^{-1}$ between 20 and $90^{\circ} \mathrm{C}$ (Sheldon and Lane, 1965) (compare with an air-dry sandy soil: heat capacity $=0.80 \mathrm{~J} \mathrm{~g}^{-1} \mathrm{~K}^{-1}$ and thermal conductivity $=0.25 \mathrm{~W} \mathrm{~m}^{-1} \mathrm{~K}^{-1}$; De Vries, 1963). The dimensions of the microlysimeters varied between the trials. All trials included lysimeters of the following 'standard' dimensions: length $=100 \mathrm{~mm}$; internal diameter $=152 \mathrm{~mm}$ (external $160 \mathrm{~mm}$ ); liner tube, internal diameter $=170 \mathrm{~mm}$. 
Note that care was taken to minimise the gap between lysimeter and lin especially for smaller diameters. Unless otherwise stated, weight loss w: recorded at the field site by a portable balance that weighed to $\pm 1 \mathrm{~g}$ (wate depth equivalent $= \pm 0.055 \mathrm{~mm}$, for an i.d. $=152 \mathrm{~mm}$ ). The lysimeter casin was inwardly tapered to a cutting edge at one end.

- Soil cores were taken manually by alternately inserting the lysimeter casin $2-3 \mathrm{~cm}$ and then excavating a slightly oversized pillar of soil to a depth $2-3 \mathrm{cr}$ below the base of the core. When the required depth was reached the core were trimmed flush at the base and were placed on a sheet metal base plate or : drainage basin and sealed with waterproof tape. The microlysimeter was the mounted in a liner tube, with its surface slightly above the soil surface tc prevent 'run-in' (Fig. 1). In some trials a mounting platform separated the base of microlysimeter and the underlying soil (Fig. 1); in others the microlysimeter rested directly on the soil. The liner positions were fixed throughoul the season in an area that was left undisturbed.

\section{Comparison of microlysimeter and gravimetric methods}

A soil bed $(1.2 \mathrm{~m} \times 2.4 \mathrm{~m} ; 0.25 \mathrm{~m}$ deep $)$ containing sieved Rowland Series soil was prepared in a glasshouse at the University of Reading. A gravel layer was laid beneath the soil to assist drainage to zero matric potential at the base, otherwise the walls and base of the soil bed were impervious. Prior to the measurement of evaporation the soil was saturated and left to drain and equilibrate while under covers for several days. After 10,13 and 18 days of evaporation, gravimetric water content measurements were made ( 8 or 12 replications) from soil depths $0-5,5-10,10-18$ and $18-25 \mathrm{~cm}$. Four 'standard' soil cores were extracted, weighed and mounted centrally along the axis of the soil bed ( $4 \mathrm{~h}$ after the gravimetric sampling on Day 10). The microlysimeters were weighed daily initially and less frequently toward the end of the experiment on Day 18. The bulk density was measured and used to calculate volumetric soil water contents and hence the evaporative loss from the surface of the soil bed in terms of equivalent depth of water.

\section{Microlysimeter diameter comparisons}

In Niger, microlysimeters of three internal diameters $(214,152$ and $56 \mathrm{~mm})$ were used to record $E_{\mathrm{s}}$. This experiment was repeated in England using internal diameters of 152 and $51 \mathrm{~mm}$ over a period including several rain events. The lysimeters used in these experiments were all $100 \mathrm{~mm}$ deep (with 6 or 12 replicates) and used soil cores that were taken on the day of recorded measurement or the day before. The smallest lysimeters were weighed to $\pm 0.1 \mathrm{~g}$ or better.

In Niger, temperatures beneath the 214 and $56 \mathrm{~mm}$ diameter microlysi- 


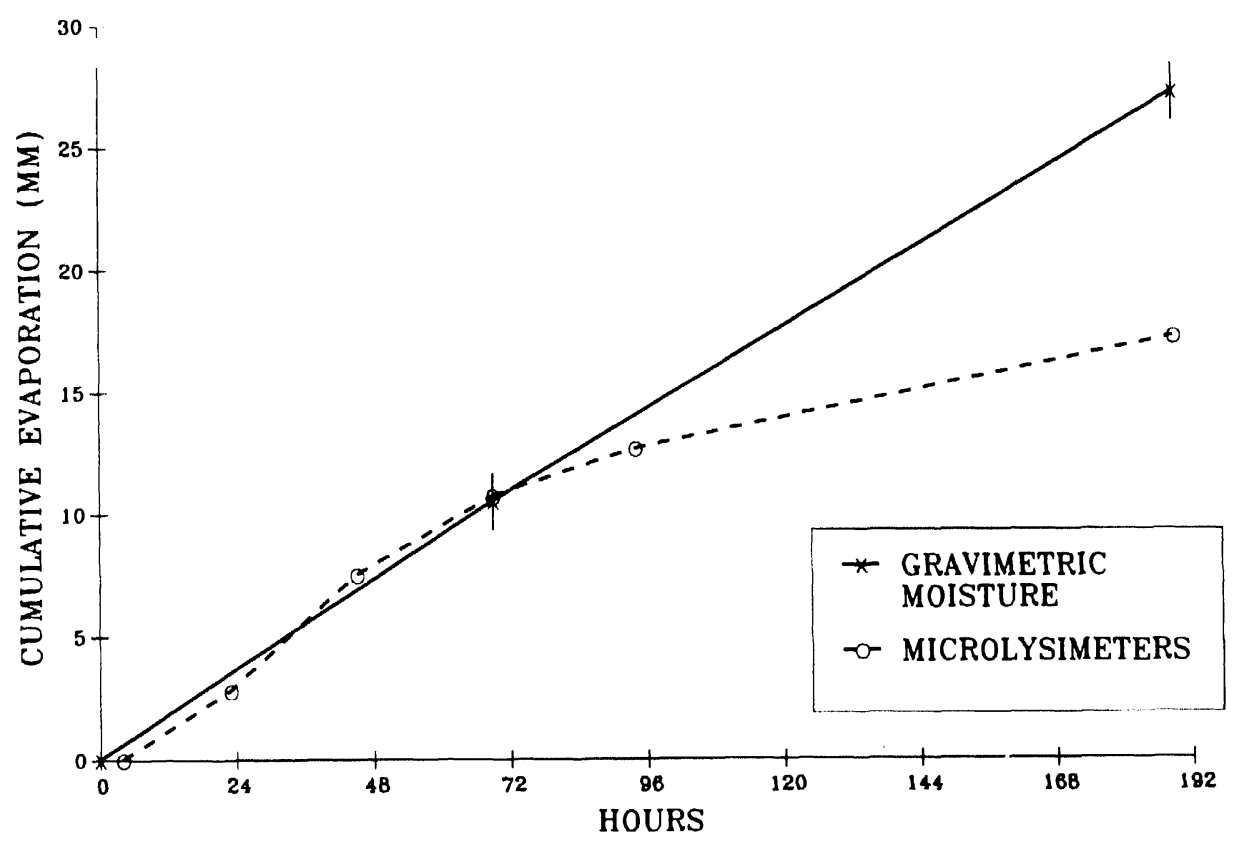

Fig. 2. Cumulative evaporation from a glasshouse soil bed with imposed zero flux plane at $250 \mathrm{~mm}$. Evaporation estimated by gravimetric soil survey to $250 \mathrm{~mm}$ and the microlysimeter method (microlysimeters $100 \mathrm{~mm}$ deep).

the University of Reading, calculated by changes in gravimetric water content of the profile and by the microlysimeter method. The largest standard error for estimation of gravimetric soil water content was $0.00156 \mathrm{~g} \mathrm{~g}^{-1}$ which gives an uncertainty of $1.2 \mathrm{~mm}$ in each estimate of cumulative evaporation (assuming a known value of bulk density). The standard error of the mean evaporation for each interval measured by the four microlysimeters is $0.1 \mathrm{~mm}$. Earlier measurements of water loss from wet soil indicated an evaporative demand of approximately $3.5 \mathrm{~mm}$ day $^{-1}$ in the glasshouse environment on sunny days.

Evaporation from the microlysimeters was consistent with the evaporation calculated by gravimetric survey until Day 4 after core extraction. The good agreement between the two methods confirms the result of Allen (1990) that microlysimeters provide an accurate measurement of $E_{\mathrm{s}}$ during rain-free periods. Figure 2 suggests that microlysimeters $100 \mathrm{~mm}$ deep remain representative of surrounding soil for 3 days under these conditions of drainage and evaporative demand. The study of Boast and Robertson (1982) suggested a lifetime of about 2.5 days for microlysimeter soil cores $70 \mathrm{~mm}$ deep exposed to a similar evaporative demand. These results both suggest that soil disturbance during lysimeter extraction and heat conduction through the lysimeter casing do not have a significant effect on $E_{\mathrm{s}}$, because these effects would be noted in the first 3 days.

It can be assumed in this trial that the zero flux plane was at the base of the 
meters were compared with those recorded in the soil profile at $100 \mathrm{~mm}$ ( Copper-constantan thermocouples were connected to a data logger to $r$ these temperatures continuously for several days (two replicates). The $n$ lysimeters used in this trial were seated on the soil at the base of the liner with the thermocouples between lysimeter base and soil.

\section{Microlysimeter 'age' comparisons}

Evaporation from two sets of microlysimeter soil cores extracted fror profile at different times was recorded in Hyderabad and in Niger. Mea ments were made in either bare soil plots or very sparse millet crops in v results were not likely to be affected by the crop. Cores were extracted the soil at a range of different times after the most recent rainfall. The $\mathrm{m}$ lysimeters were of 'standard' size at both locations.

In addition to these measurements, $E_{\mathrm{s}}$ was measured beneath a mc millet crop in Hyderabad grown in the 1990 dry season with regular ir: tion. The height of the crop was $1.5 \mathrm{~m}$, row spacing $0.5 \mathrm{~m}$ and leaf area i1 2. Following an irrigation of $45 \mathrm{~mm}, E_{\mathrm{s}}$ was measured by 12 microlysime six of which were newly extracted from the plot every 2 days so that microlysimeter was used for 4 days before being discarded. Microlysime were taken in pairs, one close to the row and the other mid-row.

\section{Microlysimeter depth comparisons}

In Niger $1991, E_{\mathrm{s}}$ from bare soil was measured by microlysimeters 100 $200 \mathrm{~mm}$ deep containing soil cores extracted simultaneously (three replicat $E_{\mathrm{s}}$ was recorded for 14 time intervals of average length $24 \mathrm{~h}$ at a range of til after last rainfall. Soil cores were discarded after one or two intervals of 1

In Hyderabad during the dry season in 1990, a bare soil plot was ploug] by bullock and then sprinkler irrigated on 18,19 and 20 January with a tc irrigation depth of $100 \mathrm{~mm}$. On 22 January, $6 \mathrm{~mm} \times 100 \mathrm{~mm}$ and $6 \mathrm{mn}$ $200 \mathrm{~mm}$ deep cores of standard diameter were extracted from the soil random locations within the irrigated area. They were weighed from January on seven occasions during a 13 day period. A second set of cores were extracted on 21 February and weighed thereafter for $7 \mathrm{da}$ There was no rain during this experimental period.

\section{Results and discussion}

\section{Comparison of microlysimeter and gravimetric methods}

Figure 2 shows cumulative evaporative loss from the glasshouse soil bed 


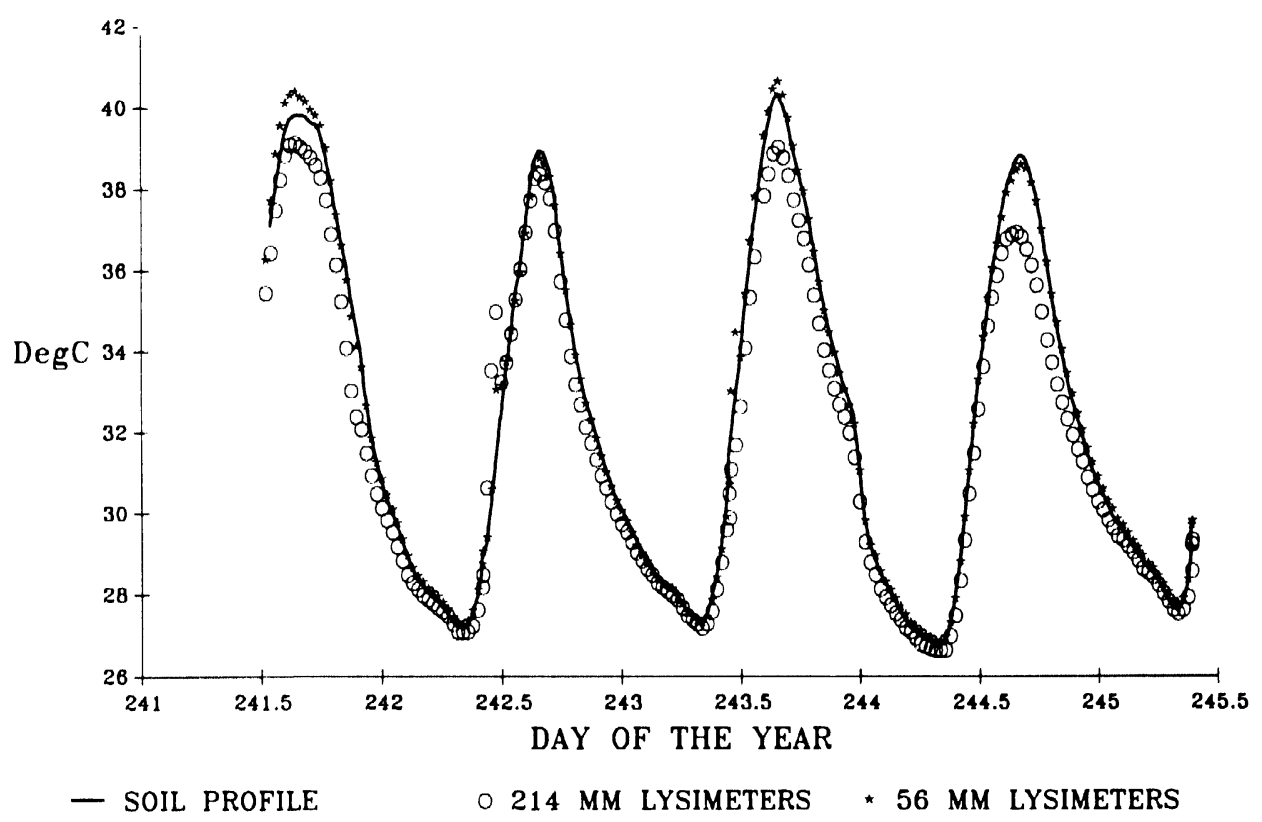

Fig. 3. Soil temperatures at $100 \mathrm{~mm}$ depth in the soil profile and at $100 \mathrm{~mm}$ directly beneath lysimeters of 214 and $56 \mathrm{~mm}$ diameter. (The short increase in temperature observed beneath lysimeters in the morning on Days 242 and 243 was the result of lysimeter removal for weighing.)

at $100 \mathrm{~mm}$ directly beneath $56 \mathrm{~mm}$ and $214 \mathrm{~mm}$ diameter lysimeters. The temperatures were virtually identical.

These findings indicate that lysimeters as small as $50 \mathrm{~mm}$ internal diameter can be used to measure $E_{\mathrm{s}}$, although more replicates may be needed to achieve the same accuracy of measurement for smaller diameters. This implies that conduction of heat through the microlysimeter casing and disturbance of soil in the extraction process are not important because no significant difference in $E_{\mathrm{s}}$ or soil temperature was noted between diameters. This may not be true if lysimeter casing or liners are of metal construction.

Villalobos and Fereres (1990) inserted perforated steel microlysimeter tubes at the beginning of the season and then excavated these tubes when required for use. This practice overcomes the problems of soil disturbance and microlysimeter insertion, but may alter the distribution of water and roots within the microlysimeter prior to use (Villalobos and Fereres, 1990). The soils used in the present study caused no major problems for extraction of cores and therefore they could be taken immediately before the period of use. In problem soils, the sampling approach of Villalobos and Fereres may be an appropriate compromise.

\section{Microlysimeter age comparisons}

Table 3 allows comparison of evaporation from microlysimeters containing soil cores that were extracted from the soil profile at different times. An 
Table 2

Mean daily evaporation ( $\mathrm{mm}$ ) from sets of microlysimeters of three diameters. Analysis of variance showed that diameter was not a significant factor in Niger or Sonning. Variability of $E_{\mathrm{s}}$ measurements for a given diameter is described by the standard error of all measurements at a site

\begin{tabular}{llll}
\hline Date & \multicolumn{2}{l}{ Internal Diameters } & \\
\cline { 2 - 4 } & $214 \mathrm{~mm}$ & $152 \mathrm{~mm}$ & $56 \mathrm{~mm}$ \\
\hline Niger & & & \\
27 August & 0.75 & 0.81 & $0.77^{\mathrm{a}}$ \\
28 August & 0.46 & 0.51 & $0.51^{\mathrm{a}}$ \\
30 August & 1.71 & 1.65 & $1.75^{\mathrm{a}}$ \\
4 October & 1.44 & 1.49 & 1.45 \\
6 October & 1.12 & 1.07 & 0.85 \\
7 October & 0.78 & 0.74 & 0.78 \\
8 October & 0.62 & 0.63 & 0.61 \\
9 October & 0.53 & 0.53 & 0.50 \\
Standard Error & 0.057 & 0.076 & 0.077 \\
& & & \\
Sonning & & & 0.71 \\
7 July & - & 0.69 & 1.20 \\
10 July & - & 1.14 & 1.75 \\
17 July & - & 1.77 & 1.85 \\
18 July & - & 1.68 & 1.53 \\
23 July & & 1.50 & 1.25 \\
24 July & $\cdots$ & 1.25 & 0.102 \\
Standard Error & & 0.068 &
\end{tabular}

${ }^{a}$ Twelve replicates were used to calculate these means, all other means were calculated from six replicates.

${ }^{h}$ The standard error given is for daily means of the same diameter assuming six replications.

soil bed $(250 \mathrm{~mm})$, well below $100 \mathrm{~mm}$ at the time the cores were extracted. Thus any flux at a depth of $100 \mathrm{~mm}$ would have been upward throughout the period following extraction and would have been exaggerated by the restricted drainage. Drainage is often unrestricted in wet field soils. Thus Fig. 2 suggests that the boundary to upward flow at the base of the microlysimeter cores imposed at the time of extraction does not have a significant effect on cumulative $E_{\mathrm{s}}$ for 3 days.

\section{Microlysimeter diameter comparisons}

Table 2 presents evaporation data from lysimeters of three diameters. Diameter had no significant effect on mean evaporation at either site (even at $P=0.1$ ). In Sonning, the standard error of mean evaporation was markedly different for the two diameters. In Niger the standard error did not follow this pattern suggesting that the increase in variability with decreasing diameter may not be large for all soils.

Figure 3 shows average temperatures at $100 \mathrm{~mm}$ depth in the soil profile and 
Table 3

Mean evaporation $(\mathrm{mm})$ from two sets of microlysimeters. Set 1 was extracted from the soil profile at an earlier time (column $X$ ) than Set 2 (column Y). Times of extraction and the evaporation measurement period are given as hours after rain

\begin{tabular}{|c|c|c|c|c|c|c|c|}
\hline \multirow{2}{*}{$\begin{array}{l}\text { Last } \\
\text { Rain } \\
(\mathrm{mm})\end{array}$} & \multirow{2}{*}{$\begin{array}{l}\text { Evap. } \\
\text { Period } \\
\text { (hours } \\
\text { after rain) }\end{array}$} & \multicolumn{2}{|c|}{ Lysimeter Set 1} & \multicolumn{2}{|c|}{ Lysimeter Set 2} & \multirow[t]{2}{*}{ Reps. } & \multirow[t]{2}{*}{ Sig." } \\
\hline & & $\begin{array}{l}\text { Time of } \\
\text { extraction } \\
X \text { (hour } \\
\text { after rain) }\end{array}$ & $\begin{array}{l}\text { Evap. } \\
(\mathrm{mm})\end{array}$ & $\begin{array}{l}\text { Time of } \\
\text { extraction } \\
Y \text { (hours } \\
\text { after rain) }\end{array}$ & $\begin{array}{l}\text { Evap. } \\
(\mathrm{mm})\end{array}$ & & \\
\hline
\end{tabular}

\begin{tabular}{|c|c|c|c|c|c|c|c|}
\hline \multicolumn{8}{|c|}{ Niger - very sparse millet crop } \\
\hline 5.9 & $10-34$ & $-{ }^{b}$ & 2.8 & 10 & 1.7 & 6 & $* *$ \\
\hline 14.7 & $20-92^{\circ}$ & - & 13.2 & 20) & 3.9 & 6 & ** \\
\hline 34.0 & $20-45^{\circ}$ & 1 & 3.5 & 20) & 2.0 & 6 & $* *$ \\
\hline 8.6 & $32-56$ & 7 & 1.7 & 32 & 1.3 & 6 & $* *$ \\
\hline 34.0 & $45-69$ & 20 & 1.2 & 45 & 1.3 & 6 & NS \\
\hline 14.7 & $94-118$ & 20) & 1.1 & 94 & 0.6 & 6 & $* *$ \\
\hline 8.4 & $96-120$ & 72 & 0.9 & 96 & 0.7 & 6 & NS \\
\hline 40.0 & $104-128$ & 80 & 0.6 & 104 & 0.6 & 6 & NS \\
\hline 8.4 & $120-144$ & 96 & 0.6 & 120 & 0.5 & 6 & NS \\
\hline 40.0 & $128-151$ & 104 & 0.4 & 128 & 0.4 & 6 & NS \\
\hline \multicolumn{8}{|c|}{ Hyderahad - hare soil } \\
\hline 22.5 & $6-54$ & & 3.7 & 6 & 2.7 & 2 & * \\
\hline $40 .()$ & $12-60^{\mathrm{c}}$ & & 8.1 & 12 & 6.2 & 5 & ** \\
\hline 22.5 & $54-102$ & 6 & 4.6 & 54 & 4.6 & 2 & NS \\
\hline 22.5 & $102-150$ & 54 & 2.9 & 102 & 2.5 & 2 & NS \\
\hline 25.0 & $108-136$ & 60 & 2.1 & 108 & 1.9 & 2 & NS \\
\hline \multicolumn{8}{|c|}{ Hyderabad - Millet crop, following irrigation } \\
\hline 45.0 & 4896 & 1 & 4.9 & 48 & 3.8 & 6 & $* *$ \\
\hline 45.0 & $96 \quad 151$ & 48 & 3.2 & 96 & 2.5 & 6 & $* *$ \\
\hline 45.0 & $151-197$ & 96 & 1.5 & 151 & 1.7 & 6 & NS \\
\hline 45.0 & $197-242$ & 151 & 0.8 & 197 & 0.7 & 6 & NS \\
\hline 45.0 & $242-317$ & 197 & 1.2 & 242 & 1.2 & 6 & NS \\
\hline
\end{tabular}

"Significance of difference of means from the two sets of lysimeters (see text): NS, not significant; * significant at $P=0.05 ;{ }^{* *}$ significant at $P=0.01$.

${ }^{\mathrm{b}}$ A negative sign (-), is displayed when the lysimeters were extracted before the rain and were subjected to rainfall in-situ. Under these conditions impeded drainage can result in high evaporation being sustained for prolonged periods.

"Marked evaporation periods are tested for significance separately, not as part of one of the three data groups.

analysis of variance of each of the three groups of data (Niger, Hyderabadbare, Hyderabad-millet) provided standard errors for differences of mean evaporation in each group. Significance of the differences in mean evaporation from sets of lysimeters of different age was tested for each evaporation period using the $t$ statistic. Data transformation was not required. The sig- 
nificance of each of three 'outlier' evaporation periods (marked in Table 3) was evaluated separately and was in agreement with the other results. Note that the data sets of Table 3 were collected in a wide range of conditions (e.g. antecedent soil water content, depth of preceding rainfall, evaporative demand) which may influence the result.

The boundary to water flow at the base of the microlysimeter and the loss of water resulting from extraction by roots (if a crop is present) will be the two factors likely to determine how long a microlysimeter remains representative of surrounding soil (its useable lifetime).

When microlysimeter Set 1 was extracted prior to rain (or during the $24 \mathrm{~h}$ following rain) evaporation is likely to be significantly higher than for Set 2 (Table 3). In these instances lysimeter Set 1 was often visibly distinguishable, having a wetter, darker surface than Set 2 and the surrounding soil. Impeded drainage in lysimeter Set 1 (extracted earlier) is the most likely cause of this znhancement of evaporation. In addition, microlysimeters subjected to rainall in situ often have a weight gain larger than the equivalent depth of rain c.f. Allen, 1990). No significant differences in $E_{\mathrm{s}}$ from bare soil were observed Jetween sets of lysimeters extracted $72 \mathrm{~h}$ or more after rain. This suggests that it these times the boundary to upward or downward movement of water at he base does not significantly influence $E_{\mathrm{s}}$ over periods of 1 to 2 days. Thus, lew sets of soil cores should be extracted at least once daily for an estimated : days after rain, and less frequently thereafter.

Sets of lysimeters extracted 2 and 4 days after irrigation in the millet plot lad significantly different values for $E_{\mathrm{s}}$. This is most likely the effect of root $x$ traction of water depleting the soil profile and causing microlysimeters to be inrepresentative of the surrounding soil. Daily extraction of soil cores may eed to continue for about 4 days after rain or irrigation in cropped soil.

The practice of adding water to an existing lysimeter after irrigation Shawcroft and Gardner, 1983; Martin et al., 1985) is not advisable as draiage occurring in the soil profile can not be accounted for in a microlysimeter nd evaporation may be over-estimated (Sadras et al., 1991).

\section{1icrolysimeter depth comparisons}

Evaporation from 100 and $200 \mathrm{~mm}$ deep lysimeters in Niger is presented in able 4. Analysis of variance showed that depth had no significant effect (at $=0.1)$ on $E_{\mathrm{s}}$ or its $\log$ transformation during either Day 1 or 2 of use.

Figure 4 shows the mean cumulative evaporation from 100 and $200 \mathrm{~mm}$ sep microlysimeters in Hyderabad during periods beginning 24 January and 1 February. For a given date, an analysis of variance was used to test the gnificance of difference in mean values of both the cumulative evaporation nce the start of the period and evaporation during the interval since the last easurement. No significant difference in cumulative evaporation from the 
Table 4

Mean evaporation $(\mathrm{mm})$ from microlysimeters 100 or $200 \mathrm{~mm}$ deep in Niger (three replications). The standard error for differences of means with data not transformed (see text) was $0.37 \mathrm{~mm}$

\begin{tabular}{lll}
\hline Date & \multicolumn{2}{l}{ Lysimeter Depth } \\
\cline { 2 - 3 } & $100 \mathrm{~mm}$ & $200 \mathrm{~mm}$ \\
\hline 8 June & 2.2 & 2.0 \\
9 June & 2.9 & 3.5 \\
10 June & 0.5 & 0.6 \\
13 June & 2.5 & 2.3 \\
16 June & 3.6 & 3.9 \\
18 June & 0.6 & 0.8 \\
19 June & 0.6 & 0.7 \\
21 June & 2.5 & 1.8 \\
27 June & 2.3 & 2.4 \\
28 June & 1.5 & 1.5 \\
4 July & 1.2 & 1.4 \\
5 July & 2.3 & 2.4 \\
8 July & 1.8 & 2.0 \\
9 July & 1.4 & 1.6 \\
\hline
\end{tabular}

andicates soil cores used for this interval were also used in the preceding interval (i.e. the line above)

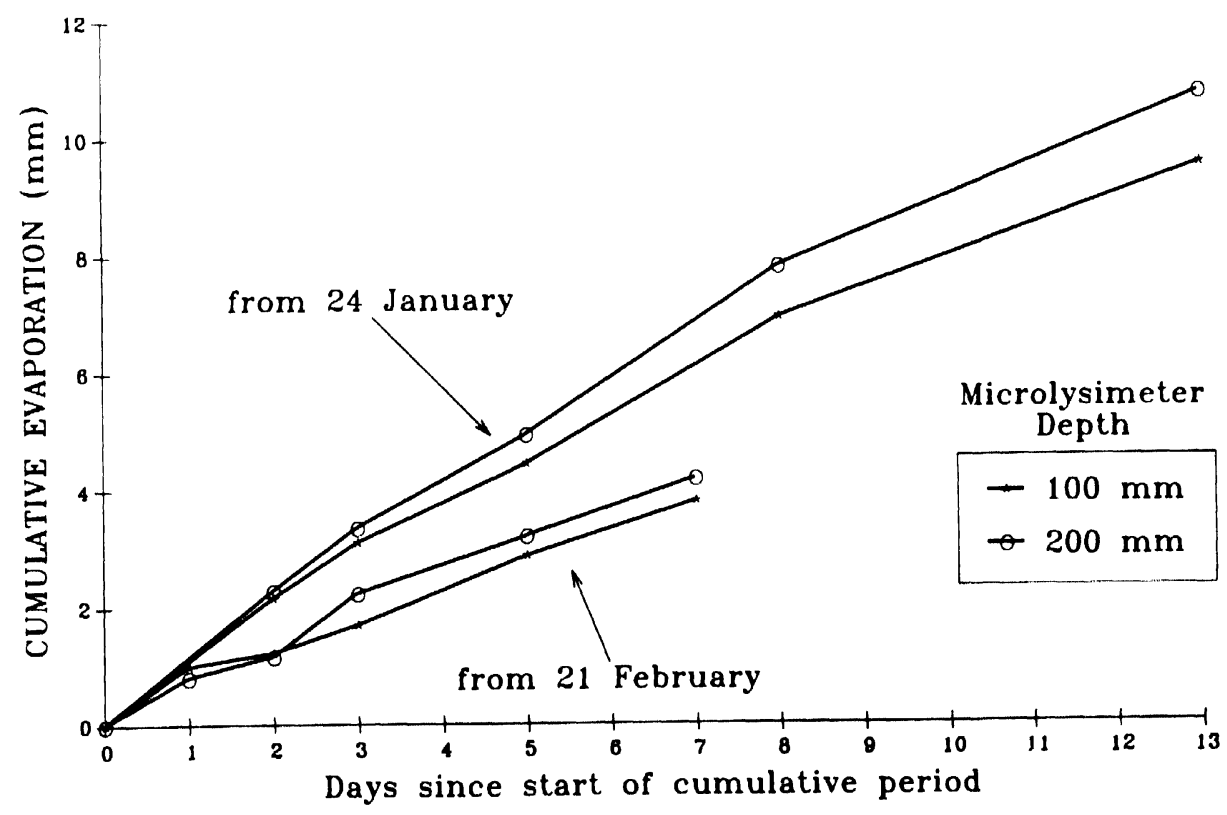

Fig. 4. Cumulative evaporation from 100 and $200 \mathrm{~mm}$ deep microlysimeters for two periods after irrigation at Hyderabad. Irrigation finished 20 January 1990, first set of cores extracted from soil profile on 22 January, second set of cores extracted 21 February. 
nicrolysimeters $100 \mathrm{~mm}$ deep and $200 \mathrm{~mm}$ deep occurred at any time during he two periods considered. For the first cumulative period, the differences in $F_{s}$ for the intervals between 5 and 8 days and 8 and 13 days were almost ignificant at $P=0.05$ and significant at $P=0.01$ respectively. (Note that he soil cores were extracted from the profile two days before the start of his period, but 2 days after irrigation had ceased.) In the second cumulative seriod no significant differences in $E_{\mathrm{s}}$ from the two depth microlysimeters vere observed for any interval.

Boast and Robertson (1982) assessed the performance of short lysimeters 44 and $70 \mathrm{~mm}$ deep) by comparison with deeper lysimeters (106 and $146 \mathrm{~mm}$ eep) assuming that the deeper lysimeters remained representative of 'field ehaviour' for a longer period. They found that a $0.5 \mathrm{~mm}$ decrease in mean umulative $E_{\mathrm{s}}$ from the $70 \mathrm{~mm}$ lysimeters relative to the mean cumulative $E_{\mathrm{s}}$ om 106 and $146 \mathrm{~mm}$ lysimeters occurred between $1.4 \pm 0.8$ and $4.0 \pm 2.0$ ays, depending on initial soil water content and evaporative demand. Our esults (Fig. 4) suggest that $100 \mathrm{~mm}$ deep microlysimeters can be used for eriods of 7 days provided they have been extracted from a bare soil profile or more days after rain. As discussed earlier (Table 3) useable lifetimes of 1 ay are required immediately following rain.

The results so far indicate that the main source of error in $E_{\mathrm{s}}$ measurement sing the microlysimeter method on bare soil is the boundary to water flow nposed at the base of the microlysimeter (depth $=z_{\text {base }}$ ) at the time of soil sre extraction. This can act as a boundary to drainage, or to upward flux of ater, i.e. $z_{\text {base }}$ is the depth of an imposed zero flux plane. If the actual zero ux plane in a bare soil profile is at a different depth such that significant water uxes occur at depth $z_{\text {base }}$, then differences in $E_{\mathrm{s}}$ would be expected to occur ztween lysimeter and the bulk soil. Differences in $E_{\mathrm{s}}$ recorded from microsimeters $100 \mathrm{~mm}$ and $200 \mathrm{~mm}$ deep would also be expected to occur, but are t observed.

Internal drainage experiments in Niger (Hartmann and Gandah, 1982; ayne et al., 1991) indicate that more than $80 \%$ of the drainage from the ip $200 \mathrm{~mm}$ of the profile occurs in the first 2 days. The added effect of aporation at the soil surface would be expected to cause the zero flux ane to reach $100 \mathrm{~mm}$ or deeper. For these sandy soils it is reasonable to isume that drainage at $100 \mathrm{~mm}$ (and $200 \mathrm{~mm}$ ) will no longer be significant if il cores are extracted 2 or more days after irrigation or rainfall.

In Niger, Payne et al. (1990) found that the zero flux boundary in bare soil ots was located between 0 and $250 \mathrm{~mm}$ for most of the 1985 growing season Id their data indicate it was often at $100 \mathrm{~mm}$. In Hyderabad on a fallow fisol, Simmonds and Williams (1989) showed that the zero flux plane had lly reached $300 \mathrm{~mm}$ after 36 days of drying. Thus, upward flux of water $200 \mathrm{~mm}$ is not likely to be large because the depth of soil contributing to $E_{\mathrm{s}}$ ill seldom be greater than $200 \mathrm{~mm}$ in these sandy soils during a rainy season. 
Figure 1 also indicates that when upward flow of water is exaggerated by maintaining zero suction at approximately $250 \mathrm{~mm}$, the effects of the boundary at the base of the microlysimeter $\left(z_{\text {base }}=100 \mathrm{~mm}\right)$ were insignificant for 3 days. It therefore seems reasonable that any upward flux of water at 100 or $200 \mathrm{~mm}$ may not influence evaporation significantly for a cumulative period of up to 7 days provided measurement started 2 or more days after rain. The length of this period may change with soil type and may not be applicable after 1 month or more without rain.

In a cropped soil, soil water contents and the zero flux plane will be lowered by root extraction. The extraction of water from the profile is expected to prevent significant upward fluxes in the soil at the level of the bare soil zero flux plane and at depth $z_{\text {base }}$ in these sandy soils. Therefore the above argument is still applicable. However, root extraction of water will not occur within the microlysimeter (as discussed earlier), and this may necessitate daily renewal of soil cores for about 4 days after rain.

\section{A Protocol for use of microlysimeters in sandy soils}

The results presented above combined with our field experience of the method allow the following list of recommendations for use of microlysimeters on sandy soils to be drawn up.

The ideal renewal schedule would involve: (1) extraction of cores from the soil profile immediately after rain, and renewal of these cores within $12 \mathrm{~h}$; (2) then daily renewal until root extraction of water from the soil to the lysimeter depth becomes insignificant (in the order of 4 days after rain); (3) thereafter, infrequent renewal (every 7 days) is all that is required. During a rainy season the next rain will most probably intervene and the schedule can begin again.

Lysimeters and liners should be constructed of PVC pipe with internal diameter $\geqslant 50 \mathrm{~mm}$, and length $\geqslant 100 \mathrm{~mm}$.

Waterproof tape and a metal base plate should be used to seal the base of the lysimeter which should fit tightly into a positioned liner tube and be seated directly on the soil at the bottom of the liner.

A portable balance that can determine weight loss to an accuracy better than the loss of $0.1 \mathrm{~mm}$ of water to evaporation, should be used.

A level pad should be installed at the field site for the balance with a box for protection against wind during measurement.

\section{Conclusions}

The microlysimeter method can provide a simple and accurate measurement of evaporation from sandy soils. In sandy soils the main sources of error that need to be considered when using microlysimeters are: (1) the root extraction of water from the lysimeter; (2) the impedance of drainage at the 
base of the lysimeter following rain. However, the above protocol allows these problems to be largely overcome.

Accounting for variability in evaporation may become the most important consideration and this may be facilitated by using the smallest diameter lysimeters. Smaller diameters may allow soil cores to be renewed more quickly and easily with minimal disruption of the crop and plot. A soil core extraction device could perhaps be used, eliminating the need for lysimeter excavation. Small diameter lysimeters may necessitate more replication, but will allow more detailed studies of soil evaporation across crop rows.

\section{Acknowledgements}

We would like to thank the Natural Resources Institute of the UK Overseas Development Administration for their financial support (EMC X0134). We are also grateful to members of staff at the ICRISAT Center, Hyderabad and the ICRISAT Sahelian Center, Niamey, for their contributions to this work. This paper was approved for publication as Journal Article JA 1373 of the International Crops Research Institute for the Semi-Arid Tropics (ICRISAT).

\section{References}

Allen, S.J., 1990. Measurement and estimation of evaporation from soil under sparse barley crops in northern Syria. Agric. For. Meteorol., 49: 291- 309.

Arkin, G.K., Ritchie, J.T. and Adams, J.E., 1974. A method for measuring first stage soil water evaporation in the field. Soil Sci. Soc. Am. Proc., 38: $951-954$.

Ashktorab, H., Pruitt, W.O., Paw U, K.T. and George, W.V., 1989. Energy balance determinations close to the soil surface using a micro-Bowen system. Agric. For. Meteorol., 46: 259274.

Boast, C.W., 1986. Evaporation from bare soil measured with high spatial resolution, In: A. Klute (Editor), Methods of Soil Analysis, Part 1. Agronomy Monograph No. 9, 2nd Edn. Am. Soc. Agron., Madison, WI, pp. 889-900.

Boast, C.W. and Robertson, T.M., 1982. A "micro-lysimeter" method for determining cvaporation from bare soil: description and laboratory evaluation. Soil Sci. Soc. Am. J., 46: 689-696.

Cooper, P.J., Keatinge, J.D.H. and Hughes, G., 1983. Crop evapotranspiration a technique for calculating its components by field measurements. Field Crops Res., 7: 299 - 312.

De Vries, D.A., 1963. Thermal properties of soils. In: W.R. Van Wijk (Editor), Physics of Plant Environment. North Holland Publishing, Amsterdam., pp. 210 235.

Hartmann, R. and Gandah, M., 1982. Hydrodynamic characterisation of a sand dune soil in Niger. Med. Fac. Landbouww. Rijksuniv. Gent, 47: 1195-1204.

Koleske, J.V. and Wartman, L.H., 1969. Polyvinylchloride. Macdonald Technical and Scientific, London, $112 \mathrm{pp}$.

Lascano, R.J. and van Bavel, C.H.M., 1986. Simulation and measurement of evaporation from a bare soil. Soil Sci. Soc. Am. J., 50: 1127-1132.

Martin, D.L., Klocke, N.L. and DeHaan, D.H., 1985. Measuring evaporation using mini-lysimeters. 
In: Advances in Evapotranspiration. Proceedings of a Conference at Chicago, IL. Am. Soc. Agric. Eng., St. Joseph, MI, pp. 231 240.

Matthias, A.D., Salehi, R. and Warrick, A.W., 1986. Bare soil evaporation near a surface pointsource emitter. Agric. Water Manage., 11: 257-277.

Payne, W.A., Wendt, C.W. and Lascano, R.J., 1990. Bare fallowing on sandy fields of Niger, West Africa. Soil Sci. Soc. Am. J., 54: 1079-1084.

Payne, W.A., Lascano, R.J. and Wendt, C.W., 1991. Physical and hydrological characterization of three sandy millet fields in Niger. In: M.V.K. Sivakumar, J.S. Wallace, C. Renard and C. Giroux (Editors), Soil Water Balance in the Sudano-Sahelian Zone. Proc. Niamey Workshop, February 1991, IAHS, No. 199, pp. 199-207.

Ritchic, J.T., 1972. Model for predicting evaporation from a row crop with incomplete cover. Water Resour. Res., 8: 1204-1213.

Sadras, V.O., Whitfield, D.M. and Connor, D.J., 1991. Regulation of evapotranspiration and its partitioning between transpiration and soil evaporation by sunflower crops: a comparison between hybrids of different stature. Field Crops Res., 28: 17 - 37.

Shawcroft, R.W. and Gardner, H.R., 1983. Direct evaporation from soil under a rowcrop canopy. Agric. Meteorol., 28: 229-238.

Sheldon, R.P. and Lane, K., 1965. Thermal conductivity of polymers I polyvinylchloride. Polymer, 6: $77-85$.

Simmonds, L.P. and Williams, J.H., 1989. Population, water use and growth of groundnut maintained on stored water. 2. Transpiration and evaporation from soil. Expl. Agric., 25: 63-75.

Villalobos, F.J. and Fereres, E., 1990. Evaporation measurements beneath corn, cotton and sunflower canopies. Agron. J., 82: 1153-1159.

Walker, G.K., 1983. Measurement of evaporation from soil beneath crop canopies. Can. J. Soil Sci., 63: $137-141$.

Wallace, J.S., Lloyd, C.R. and Sivakumar, M.V.K., 1992. Measurements of soil, plant and total evaporation from millet in Niger. Agric. For. Meteorol., 63: 149-169. 